\title{
Obsessive-compulsiveness and impulsivity in a non-clinical population of adolescent males and females
}

\author{
Chiang-shan Ray Li ${ }^{\text {a,b,* }}$, Sue-Huei Chen ${ }^{\mathrm{c}}$ \\ ${ }^{a}$ Medical Research Center, Chang Gung Memorial Hospital, Tao-yuan, Taiwan \\ ${ }^{\mathrm{b}}$ Department of Psychiatry, Yale University School of Medicine, New Haven, CT, United States \\ c Department of Psychology, National Taiwan University, Taipei, Taiwan
}

Received 1 December 2005; received in revised form 15 February 2006; accepted 2 May 2006

\begin{abstract}
Obsessive-compulsive and impulsive behaviors co-occur in certain psychiatric conditions. Some have suggested that these disturbances constitute a spectrum of altered psychologies and behaviors that share an underlying neuropathology. We investigate here whether obsessive-compulsiveness and impulsivity reflect related psychological dimensions in a non-clinical adolescent population. Out of 720 high-school students, 672 and 682 completed a questionnaire interview with a Chinese version of the Maudsley Obsessive-Compulsive Inventory (MOCI) and the Barratt Impulsiveness Scale (BIS-11), respectively. Both MOCI and BIS-11 demonstrated good overall internal consistency, each with three major factors identified with Principal Component Analysis. In the 638 participants who completed both questionnaires, the total MOCI and BIS-11 scores did not correlate with each other. However, the MOCI factor "repetitive checking and attention to details" correlated negatively with the BIS- 11 factor "inability to plan and look ahead" for all participants, and for males and females separately. The same MOCI factor also correlated negatively with the BIS-11 factors "lack of perseverance and self-control" and "novelty-seeking and acting without thinking" for all participants, and for females but not for males. The MOCI factor "doubt and intrusive thoughts" correlated positively with the BIS11 factor "lack of perseverance and self-control" for all participants, and for males but not for females. These results suggested that the relationship between obsessive-compulsiveness and impulsivity as measured by the MOCI and the BIS-11 is complicated, with gender playing an important modulatory role. We discuss the relevance of these findings to developing a conceptual scheme to characterize and study the neurobiological basis of obsessive-compulsive and impulsive behaviors.
\end{abstract}

(C) 2006 Elsevier Ireland Ltd. All rights reserved.

* Corresponding author. Present address: Connecticut Mental Health Center, S103, Department of Psychiatry, Yale University, 34 Park Street, New Haven, CT 06519, United States. Tel.: +1 203974 7354; fax: +1 2039747366 .

E-mail address: chiang-shan.li@yale.edu (C.-S.R. Li).

\section{Introduction}

Obsessive-compulsiveness and impulsivity co-occur in a number of psychiatric conditions (McElroy et al., 1994). Hollander et al. viewed these altered behaviors as the two core manifestations of the obsessive-compulsive spectrum disorders (OCSDs), which are disorders that involve an inability to inhibit or delay repetitive behaviors and the share important clinical characteristics 
with obsessive-compulsive disorder (OCD, Hollander and Wong, 1995; Hollander et al., 1996). Compulsivity, typified by the core symptoms of OCD, is characterized by exaggerated perception of harm and excessive, overreflective responses, and difficult-to-control harm or risk avoidance behaviors. Impulsivity, on the other hand, is characterized by underestimation of harm, non-reflective responses, and difficult-to-control desires and repetitive behaviors to obtain pleasure and gratification. Although compulsivity and impulsivity seemingly describe two opposite extremes of these altered behaviors, most OCSDs can be characterized by a combination of compulsivity and impulsivity to varying extents. In fact, both of these behavioral features are often observed simultaneously or at different times in the course of the same illness (Hollander and Wong, 1995; Skodol and Oldham, 1995; Stein et al., 1996).

Evidence supporting the continuity of symptomatology and disease categories in OCSD comes mostly from the patterns of co-morbidity observed between OCD and OCSD. For instance, studies have shown higher rates of lifetime diagnosis of body dysmorphic disorder (BDD) in OCD patients (Simeon et al., 1995) and higher rates of BDD in case probands and relatives of OCD patients compared with non-proband controls (Bienvenu et al., 2000). Other studies have found a high co-occurrence of OCD in patients with BDD (Phillips et al., 1994; Veale et al., 1996), suggesting a strong diagnostic and etiological relationship between the two disorders. On the other hand, the association of other OCSDs, particularly those presenting predominantly impulsive behaviors, with OCD has been less consistent (Swedo and Leonard, 1992; Christenson et al., 1991; Bienvenu et al., 2000; Lochner et al., 2005). For instance, while some studies showed that patients with pathological gambling report more obsessions and compulsions, other studies failed to demonstrate increased OC symptoms in these patients (Frost et al., 2001; Kim and Grant, 2001; Anholt et al., 2004). Moreover, a recent study suggested important contrasting clinical characteristics between OCD and trichotillomania, including the age of onset of illness and treatment response to serotonin reuptake inhibitors (Lochner et al., 2005). Therefore, despite the symptomatological overlaps and possible etiological relationship among the OCSDs, the differential association of various OCSDs with compulsivity and impulsivity seems to suggest the utility of using the two behavioral features as opposing concepts in characterizing these disease entities.

Hoehn-Saric and Barksdale (1983) compared OCD patients with a history of poor impulse control with those without such history in a small sample of subjects. They found that, although both groups reported comparable
OC symptoms, the impulsive group rated significantly higher on disturbances during childhood. They suggested that poor impulse control was related to disturbances that had already manifested themselves during childhood, while the OCD was superimposed at a later time. A more recent study sought to determine whether OCD patients with impulsive features constituted a distinct subtype of OCD (Matsunaga et al., 2005). Of more than 150 adult OCD patients, about one third had concurrent impulse control disorder (ICD), and could be differentiated from those without ICD by younger age of onset, more severe psychopathology and poor treatment outcome. The authors suggested that these results argued against a dichotomy between compulsive and impulsive disorders and that both behavioral features could be used as orthogonal dimensions to characterize related psychiatric conditions (Lacey and Evans, 1986; Rasmussen and Eisen, 1994; McElroy et al., 1995).

Taken overall, these studies have provided a prolific body of evidence suggesting the complexity in characterizing OCSDs in terms of obsessive-compulsiveness

(a)

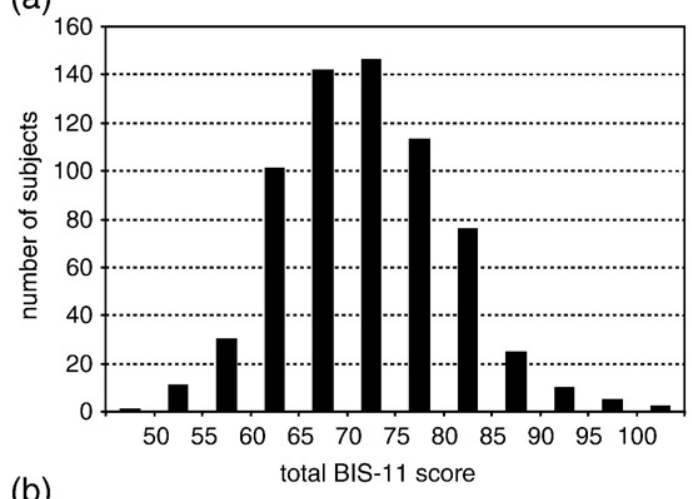

(b)

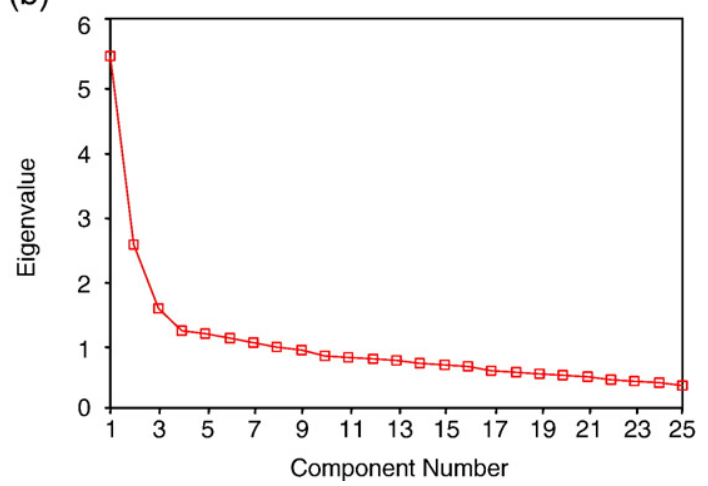

Fig. 1. (a) The distribution of the BIS-11 total scores and (b) Scree test. The first three components appear to have an eigenvalue distinctively larger than the others. 
and impulsivity. However, the question remains whether these two behavioral features should best be used as correlated, opposing (negatively correlated) or orthogonal dimensions in conceptualizing OCSDs and in clinical psychological studies in general. The current study attempts to address this question by studying the association of impulsivity and obsessive-compulsiveness in a non-clinical sample. In particular, to circumvent the issue of developmental or adaptive superimposition of personality traits as suggested by Hoehn-Saric and Barksdale (1983), we examined for this association in an adolescent population. A positive association between these two personality traits would suggest a common biological basis of impulsivity and obsessive-compulsiveness and continuity in these behavioral attributes. A negative association would suggest conceptual diagonalization of these two behavioral features and impose important constraints on their underlying neurobiology. Finally, a lack of association would suggest that impulsivity and obsessive-compulsiveness represent different psychological constructs, without ruling out the possibility that one personality trait might affect the development of the other as the full personality profiles unfold for these individuals later in their lives.
A concurrent goal of the present study is to assess the association of obsessive-compulsive and impulsive personality features in an adolescent population. Previous work has demonstrated high co-morbidity between attention deficit hyperactivity disorder, Tourette's disorder and OCD, and has suggested an etiological link between obsessive-compulsive and disinhibitory psychopathologies in adolescents and younger children (Sherman et al., 1998; Stephens and Sandor, 1999; Niehaus et al., 2000; Cath et al., 2001; Apter et al., 2003; Guerrero et al., 2003; Mathews et al., 2004). It would thus be of interest to examine whether and which specific aspects of the association between the obsessive-compulsive and impulsive symptomatologies extend to a non-clinical population.

\section{Methods}

\subsection{Subjects}

Adolescents $(n=720 ; 353$ males, $16.9 \pm 1.3$ years of age; 367 females, $16.8 \pm 1.3$ years of age; no difference in age, $P=0.39$, two-sample $t$ test) from the Ho-Ping High School of Taipei city participated in the study. These students belonged to 15 classes of the senior high

Table 1

Factor loadings of 25 items of BIS-11

\begin{tabular}{|c|c|c|c|c|}
\hline \multirow[t]{2}{*}{ Item } & \multirow[t]{2}{*}{ Question } & \multirow{2}{*}{$\frac{\text { Factor } 1}{\text { Inability to plan }}$} & \multirow{2}{*}{$\frac{\text { Factor } 2}{\text { Lack of self-control }}$} & \multirow{2}{*}{$\frac{\text { Factor } 3}{\text { Novelty-seeking }}$} \\
\hline & & & & \\
\hline $1^{\mathrm{a}}$ & I plan task carefully & 0.649123 & 0.119744 & 0.081926 \\
\hline 2 & I do things without thinking & 0.400987 & 0.262666 & 0.353052 \\
\hline 3 & I make up my mind quickly & -0.01199 & -0.02074 & 0.550733 \\
\hline 4 & I am happy-go-lucky & -0.01828 & 0.075552 & 0.544676 \\
\hline 5 & I don’t "pay attention" & 0.298339 & 0.438867 & 0.196955 \\
\hline 6 & I have "racing" thoughts & -0.06022 & 0.420681 & 0.206281 \\
\hline $7^{\mathrm{a}}$ & I plan trips well ahead of time & 0.536917 & 0.156909 & 0.008719 \\
\hline $8^{\mathrm{a}}$ & I am self-controlled & 0.439178 & 0.378176 & -0.01335 \\
\hline $9^{a}$ & I concentrate easily & 0.460853 & 0.421445 & -0.11692 \\
\hline $10^{\mathrm{a}}$ & I save regularly & 0.13192 & 0.302715 & 0.00582 \\
\hline 11 & I "squirm" at plays or lectures & 0.143673 & 0.222001 & 0.102436 \\
\hline $12^{\mathrm{a}}$ & I am a careful thinker & 0.704205 & -0.01386 & 0.114718 \\
\hline $13^{\mathrm{a}}$ & I plan for job security & 0.251048 & 0.316447 & -0.07379 \\
\hline 14 & I say things without thinking & 0.204441 & 0.222235 & 0.396935 \\
\hline 16 & I change jobs & -0.17641 & 0.117664 & 0.457651 \\
\hline 17 & I act "on impulse" & 0.250105 & 0.368176 & 0.546521 \\
\hline 18 & I get easily bored solving thought problems & 0.234682 & 0.321901 & 0.199386 \\
\hline 19 & I act on the spur of the moment & 0.023073 & 0.240371 & 0.422732 \\
\hline $20^{\mathrm{a}}$ & I am a steady thinker & 0.68637 & 0.131961 & 0.031284 \\
\hline 22 & I buy things on impulse & 0.082566 & 0.439607 & 0.285732 \\
\hline 24 & I change hobbies & -0.02102 & 0.307615 & 0.180089 \\
\hline 25 & I spend or charge more than I earn & 0.162352 & 0.576056 & 0.240037 \\
\hline 26 & I have outside thoughts when thinking & 0.129585 & 0.603491 & 0.090319 \\
\hline 28 & I am restless at lectures or talks & 0.196578 & 0.46714 & 0.106042 \\
\hline $30^{\mathrm{a}}$ & I plan for the future & 0.41924 & 0.131429 & -0.13109 \\
\hline
\end{tabular}

${ }^{\text {a }}$ Indicates reverse scoring; bold typeface indicates highest factor loading for each item. 
and six classes of the junior high, selected based on their availability on the day the questionnaire interviews were conducted. No formal psychiatric evaluation was performed for our subjects. However, none of them reported history of neurological insult, use of illicit substances or current use of psychotropic medications. Written consent was obtained from all of the participants after the nature and the procedures of the study were explained in detail, in strict accordance with the institute guidelines.

\subsection{Barratt Impulsiveness Scale version 11 (BIS-11)}

Participants completed a Chinese version of the Barratt Impulsiveness Scale version 11 (BIS-11, Patton et al., 1995) and the Maudsley Obsessive-Compulsive Inventory (Hodgson and Rachman, 1977) during an extended break in school. The BIS-11 is a 30-item self-report questionnaire designed to measure impulsivity. All items are measured on a 4-point scale $(1=$ rarely/never; $2=$ occasionally; 3 = often; 4 = almost always/always). The total score thus ranges from 30 to 120, with a higher score indicating higher impulsivity. Eleven of the 30 items are scored in a reverse order to avoid response bias. The BIS11 has been translated into Italian and Japanese with good internal consistency and test-retest reliability (Fossati et al., 2001; Someya et al., 2001). Factor analysis revealed three independent components in the BIS-11 (Patton et al., 1995): attentional impulsiveness (assessing the ability to focus on the task at hand); motor impulsiveness (assessing the tendency to act on the spur of the moment); and nonplanning impulsiveness (assessing the tendency to plan and think carefully).

\subsection{Maudsley Obsessive-Compulsive Inventory (MOCI)}

The Maudsley Obsessive-Compulsive Inventory (MOCI) is also a 30-item self-report questionnaire, designed to measure obsessive-compulsiveness (Hodgson and Rachman, 1977). All items are answered true or false, yielding a maximum score of 30 with higher score indicating greater obsessive-compulsiveness. Fifteen of the 30 items are scored in a reverse order to avoid response bias. Factor analysis revealed four subscales: washing, checking, slowness and doubting (Hodgson and Rachman, 1977). Earlier studies have suggested that the MOCI exhibits good reliability and predictive validity (Dent and Salkovskis, 1986; Sternberger and Burns, 1990). The MOCI has previously been translated into Chinese, Hebrew, Japanese, and Norwegian for use in a non-clinical population with modest internal consistency (Chan, 1990; Tadai et al., 1995; Zohar and Bruno, 1997; Støylen et al., 2000).

\section{Results}

\subsection{Item and factor analysis of the BIS-11 and MOCI}

The total impulsivity (BIS-11) score of all 682 participants who completed the BIS-11 questionnaire ranged from 47 to 108 (mean \pm standard deviation: $72.5 \pm 8.7$; $72.7 \pm 8.7$, males; $72.2 \pm 8.7$, females, $P=0.44$, twosample $t$ test) and followed a skewed distribution with a skewness of 0.29 and a kurtosis of 0.38 (Fig. 1a). We assessed the internal consistency of this Chinese version of the BIS-11 by performing reliability analysis. Five of the 30 items demonstrated a corrected item-total correlation less than 0.1 (compared with $0.318 \pm 0.159$, mean \pm standard deviation) and were removed from further analysis. The remaining 25 items of the BIS-11 had a Cronbach's $\alpha$ of 0.834 . We performed a factor analysis of these 25 items by extraction with principal component analysis (PCA). The first three components had an eigenvalue greater than 1.5 , met the criteria of the scree test, and explained $37.9 \%$ of the variance (Fig. 1b). We followed with a varimax factor rotation of the data

(a)
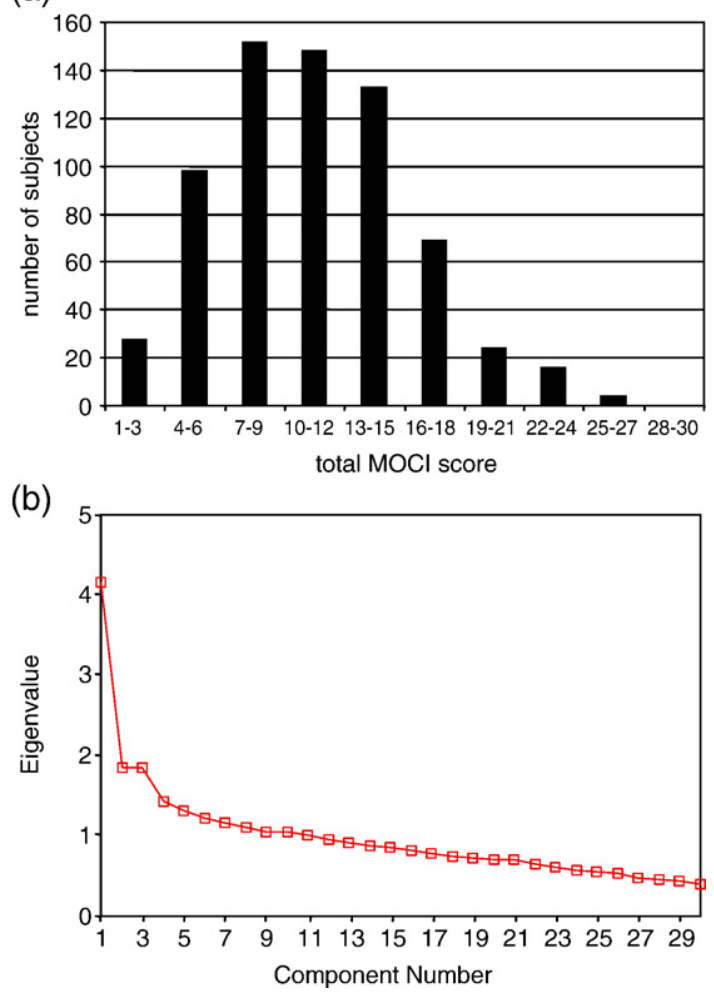

Fig. 2. (a) The distribution of the MOCI total scores and (b) Scree test. The first three components appear to have an eigenvalue distinctively larger than the others. 
Table 2

Factor loadings of all 30 items of MOCI

\begin{tabular}{|c|c|c|c|c|}
\hline \multirow[t]{2}{*}{ Item } & \multirow[t]{2}{*}{ Question (abbreviated) } & \multirow{2}{*}{$\frac{\text { Factor } 1}{\text { Repetitive checking }}$} & \multirow{2}{*}{$\frac{\text { Factor } 2}{\text { Intrusive thoughts }}$} & \multirow{2}{*}{$\frac{\text { Factor } 3}{\text { Concern over cleanliness }}$} \\
\hline & & & & \\
\hline 1 & Avoiding public telephone & 0.065054 & 0.100936 & 0.137553 \\
\hline 2 & Getting nasty thoughts & -0.02989 & 0.443947 & 0.057605 \\
\hline 3 & More concerned about honesty & 0.106778 & 0.114422 & -0.0599 \\
\hline 4 & Being late for getting through things on time & -0.13417 & 0.21749 & 0.164616 \\
\hline $5^{\mathrm{a}}$ & Not worrying about touching an animal & 0.231637 & 0.006784 & 0.064446 \\
\hline 6 & Checking things several times & 0.514722 & 0.211642 & 0.11065 \\
\hline 7 & Having a strict conscience & 0.213626 & 0.097291 & -0.02707 \\
\hline 8 & Being upset by unpleasant thoughts & 0.054598 & 0.643769 & 0.027306 \\
\hline $9^{\mathrm{a}}$ & Not worrying about bumping into somebody & 0.168863 & 0.193871 & 0.026242 \\
\hline 10 & Having doubts about simple everyday things & 0.158346 & 0.568125 & 0.062662 \\
\hline $11^{\mathrm{a}}$ & Not having strict parents & 0.15804 & 0.003953 & 0.016073 \\
\hline 12 & Getting behind work due to repetition & 0.06127 & 0.391084 & 0.095642 \\
\hline $13^{\mathrm{a}}$ & Using an average amount of soap & 0.205997 & 0.107254 & 0.266564 \\
\hline 14 & Believing in unlucky numbers & 0.13929 & 0.225003 & 0.16336 \\
\hline $15^{\mathrm{a}}$ & Not checking letters before mailing & 0.223282 & 0.146151 & 0.170454 \\
\hline $16^{\mathrm{a}}$ & Not taking long to dress in the morning & 0.003499 & -0.01607 & 0.661354 \\
\hline $17^{\mathrm{a}}$ & Not overconcerned about cleanliness & 0.284859 & -0.03945 & 0.250862 \\
\hline 18 & Attending too much to detail & 0.311622 & 0.323565 & -0.0108 \\
\hline $19^{\mathrm{a}}$ & Using well-kept toilets without any hesitation & 0.208068 & 0.058623 & -0.00119 \\
\hline 20 & Checking repeatedly & 0.47991 & 0.369371 & 0.088145 \\
\hline $21^{\mathrm{a}}$ & Not overconcerned about germs and diseases & 0.430932 & 0.045302 & 0.163533 \\
\hline $22^{\mathrm{a}}$ & Not checking more than once & 0.623168 & 0.144363 & 0.064406 \\
\hline $23^{\mathrm{a}}$ & Not sticking to a strict routine & 0.33603 & 0.04301 & 0.060312 \\
\hline $24^{\mathrm{a}}$ & Not feeling hands dirty after touching money & 0.254077 & 0.043391 & -0.00066 \\
\hline $25^{\mathrm{a}}$ & Not counting when doing a routine task & 0.373462 & 0.036533 & 0.033973 \\
\hline 26 & Taking long to wash in the morning & -0.05523 & 0.042899 & 0.739818 \\
\hline $27^{\mathrm{a}}$ & Not using a great deal of antiseptics & 0.19602 & 0.043384 & 0.255657 \\
\hline 28 & Spending time checking things over & 0.363509 & 0.401283 & 0.158349 \\
\hline $29^{\mathrm{a}}$ & Not taking long in hanging and folding clothes & 0.019448 & 0.118373 & 0.210856 \\
\hline 30 & Feeling things have not been done right & 0.171518 & 0.523633 & 0.101642 \\
\hline
\end{tabular}

${ }^{a}$ Indicates reverse scoring; bold typeface indicates highest factor loading for each item.

with maximum likelihood extraction of three factors. Table 1 shows loadings of all 25 items on these three factors. These three factors accounted for $29.9 \%$ for the total variance, and could represent a deficit in planning and looking ahead (factor 1), lack of perseverance and self-control (factor 2), and propensity toward novelty-

Table 3

Pearson correlation among MOCI and BIS-11 sub-scores

\begin{tabular}{|c|c|c|c|c|c|c|c|}
\hline & & \multicolumn{2}{|l|}{ MOCI F1 } & \multicolumn{2}{|l|}{ MOCI F2 } & \multicolumn{2}{|l|}{ MOCI F3 } \\
\hline & & \multicolumn{2}{|c|}{ Repetitive checking } & \multicolumn{2}{|c|}{ Intrusive thoughts } & \multicolumn{2}{|c|}{$\begin{array}{l}\text { Concern about } \\
\text { cleanliness }\end{array}$} \\
\hline & & Pearson $r$ & $P$ value & Pearson $r$ & $P$ value & Pearson $r$ & $P$ value \\
\hline \multirow[t]{3}{*}{ All $(n=638)$} & BIS-11 F1, inability to plan & -0.27 & $<\mathbf{0 . 0 0 0 1}$ & 0 & 0.910906 & 0.02 & 0.542992 \\
\hline & BIS-11 F2, lack of self-control & -0.17 & $<0.0001$ & 0.18 & $<0.0001$ & 0.12 & 0.002852 \\
\hline & BIS-11 F3, novelty-seeking & -0.16 & $<0.0001$ & -0.03 & 0.451779 & -0.02 & 0.681904 \\
\hline \multirow[t]{3}{*}{ Males $(n=312)$} & BIS-11 F1, inability to plan & -0.25 & $<0.0001$ & -0.01 & 0.841387 & 0.07 & 0.220843 \\
\hline & BIS-11 F2, lack of self-control & -0.14 & 0.013623 & 0.23 & $<0.0001$ & 0.16 & 0.004850 \\
\hline & BIS-11 F3, novelty-seeking & -0.12 & 0.038288 & 0.05 & 0.413723 & 0.02 & 0.767491 \\
\hline \multirow[t]{3}{*}{ Females $(n=326)$} & BIS-11 F1, inability to plan & -0.29 & $<\mathbf{0 . 0 0 0 1}$ & -0.03 & 0.531834 & -0.01 & 0.915575 \\
\hline & BIS-11 F2, lack of self-control & -0.22 & $<0.0001$ & 0.09 & 0.104434 & 0.10 & 0.085224 \\
\hline & BIS-11 F3, novelty-seeking & -0.19 & $<\mathbf{0 . 0 0 0 5}$ & -0.10 & 0.080936 & -0.03 & 0.544772 \\
\hline
\end{tabular}

Note. bold type indicates statistical significance. 
seeking and acting without thinking (factor 3), respectively. We computed the total score of the 25 items and the total sub-score of the three factors for all 682 participants.

The total MOCI scores for all 672 participants who completed the MOCI questionnaire ranged from 1 to 25 (mean \pm standard deviation: $11.0 \pm 4.8 ; 11.6 \pm 4.8$, males; $10.5 \pm 4.8$, females, $P<0.005$, two-sample $t$ test). The distribution of the total MOCI scores is negatively skewed with a skewness of 0.40 and a kurtosis of -0.13 (Fig. 2a). Item analysis of this Chinese version of MOCI showed that the corrected item-total correlation of all 30 items averaged $0.265 \pm 0.110$ (mean \pm standard deviation) with a Cronbach's $\alpha$ of 0.756 . Component extraction with principal component analysis (PCA) in conjunction with the scree test suggested that only the first three components be identified (Fig. 2b). We thus performed varimax factor rotation of the data with maximum likelihood extraction of three factors. Table 2 shows loadings for all 30 items on these three factors, which accounted for $19.8 \%$ of the total variance and could indicate repetitive checking (factor 1), doubting and intrusive thoughts (factor 2), and concern about appearance and cleanliness (factor 3), respectively. We computed the total MOCI scores and the total subscores of these three factors for all 672 participants.

\subsection{Correlation between MOCI and BIS-11 total scores and factor sub-scores}

We performed linear regressions of the total BIS-11 scores against total MOCI scores for 638 participants who completed both questionnaires and for male and female participants separately. We also performed linear regressions of the total sub-score of each of the three BIS-11 factors against the total sub-score of each of the three MOCI factors, for all subjects combined and for male and female subjects separately. Because of these multiple analyses (30 in total), a family-wise Bonferroni correction was used to adjust for statistical significance. A $P$ value of less than $0.001(<0.05 / 30)$ was considered statistically significant.

The results showed that the total BIS-11 score and the total MOCI score did not correlate with each other, when male and female participants were combined or when male and female participants were examined separately (all $P$ 's $>0.04$ ). Table 3 shows the results of linear regressions between BIS-11 and MOCI factor subscores. There is a significant negative correlation between BIS-11 factor 1 and MOCI factor 1 sub-scores, for male and female participants combined, and for males and females separately. There was also a significant negative correlation between BIS-11 factor
2 and MOCI factor 1 sub-scores, for male and female participants combined, and for female but not male participants. We also found a significant positive correlation between BIS- 11 factor 2 and MOCI factor 2 subscores for male and female participants combined and for male but not female participants. Finally, there was a significant negative correlation between the BIS-11 factor 3 and MOCI factor 1 sub-scores for male and female participants combined and for female but not male participants. None of the other correlations were statistically significant.

Given that the loading of some items in these two questionnaires appears exceedingly low, compared with others, we have re-computed the total scores and re-run all the regression analyses by including only those items whose loading was greater than 0.3 ( 1 and 15 items in the BIS-11 and MOCI were excluded, respectively, under this criterion). The results remained identical (not shown): significant correlations remained significant and vice versa.

\section{Discussion}

\subsection{Factor structure of this Chinese version of the MOCI and the BIS-11}

Hodgson and Rachman identified four components from principal component analysis (PCA) of the 30-item MOCI in patients with OCD: checking, cleaning, slowness and doubting (Hodgson and Rachman, 1977). Sanavio and Vidotto administered an Italian version of the MOCI to 868 young adult students and identified three components: checking and excessive worries; fear of contamination and excessive cleaning; and doubts and intrusive thoughts (Sanavio and Vidotto, 1985). A fourth component, obsessional slowness, was only identified in male subjects. Three major factors were identified from a study in which the MOCI was administered to 183 English-speaking Chinese medical students: repetitive checking; fear of contamination; and doubting and rumination (Chan, 1990). Other assessments also indicated that the slowness component is of less importance in explaining factor loadings of the MOCI (Emmelkamp et al., 1999). Our current results also suggested three independent factors associated with this Chinese version of the MOCI: repetitive checking, doubts and intrusive thoughts, and concern about appearance and cleanliness, in good agreement with previous studies. Therefore, the MOCI appears to be well characterized by three conceptual dimensions including repetitive checking, excessive cleaning, and doubts and intrusive thoughts, although the item loadings may not be exactly the same across different languages and cultures. 
The BIS-11 administered to college undergraduates, psychiatric inpatients and prison inmates demonstrated six components in PCA followed by an oblique, promax rotation (Patton et al., 1995). Patton et al. then combined them into three non-orthogonal components: attentional impulsiveness, motor impulsiveness and non-planning impulsiveness. A subsequent study employing confirmatory factor analysis showed that the Japanese version of the BIS-11 demonstrated a similar factor structure (Someya et al., 2001). The Italian version of the BIS-11 also shared similar psychometric properties, although the item loadings differed from those of the English version (Fossati et al., 2001). Our Chinese version of the BIS-11 appeared to demonstrate a slightly different factor structure from the original and the other translations. PCA for all 30 items identified only two components with the scree test (data not shown). Therefore, we have examined closely the internal consistency for each individual item and removed those with a corrected item-total correlation below 1.5 standard deviations of the mean. PCA with orthogonal rotation identified three factors with the remaining 25 items. These three factors seem to represent similar psychological constructs as those originally identified: inability in planning and looking ahead (non-planning impulsiveness), lack of perseverance and self-control (attentional impulsiveness), and novelty-seeking and acting without thinking (motor impulsiveness), with fair overlap of item loadings.

It is worth noting that although the factor structures of the two questionnaires appear to be analogous to those identified from the questionnaires in the original and other languages, the mean total scores can differ greatly. For instance, the mean BIS-11 obtained in Italian college undergraduates (mean age $=23$ years) is around 64.1, very close to the mean of 63.8 obtained in a U.S. sample (Fossati et al., 2001). However, the Japanese version of the BIS-11 as administered in an adult population (mean age $=32$ years) showed a mean total score of 39.3 (Someya et al., 2001). Our current study showed a mean BIS-11 score of 72.5 in an adolescent population (mean age $=17$ years). Therefore, impulsivity as assessed by the different translations of the BIS-11 can differ greatly among cultures and between different age groups. Similarly, racial differences in obsessive-compulsiveness as assessed by the MOCI have also been reported (Thomas et al., 2000).

\subsection{Correlation between obsessive-compulsiveness and impulsivity}

The current study showed that the total MOCI and BIS-11 scores did not correlate with each other either for all participants or for male and female participants examined separately. In an earlier work, an obsessivecompulsiveness scale (OCS) and the BIS-10 were administered to over 50 recovering patients with alcohol use disorders and over 350 community control subjects (Ketzenberger and Forrest, 2000). The study found that while alcoholic patients scored significantly higher on impulsiveness than non-alcoholic patients, the impulsiveness and obsessive-compulsiveness scores did not correlate with each other, for either group of subjects. This lack of correlation seemed to suggest that obsessive-compulsiveness and impulsivity be treated as non-related, orthogonal behavioral features or personality traits.

On the other hand, the factor sub-scores of the MOCI and the BIS-11 demonstrated significant correlations even after correction for multiple comparisons. There was a significant negative correlation between MOCI factor 1 (repetitive checking) and BIS-11 factor 1 (inability in planning and looking ahead) for all participants and for male and female participants separately. The factor of repetitive checking also showed a negative correlation with BIS-11 factor 2 (lack of perseverance and selfcontrol) and factor 3 (novelty-seeking and acting without thinking) for male and female participants combined and for female participants only. It thus appears that repetitive checking stands out as a compulsive trait in showing a negative association with impulsivity. Those who are compulsive checkers are better able to plan ahead, persevere, and refrain from seeking novelty and quick decision making, an association that the current results suggest to be more robust in females than in males. This result appears to be consistent with a recent study showing that adolescent patients with OCD are less impulsive than controls (Shoval et al., 2006). MOCI factor 2 (doubting and intrusive thoughts) correlated positively with BIS-11 factor 2 (lack of perseverance and self-control), an association that appeared to be carried solely by male participants. Therefore, men who have frequent doubts and thought intrusions tend not to be able to sustain attention on a current activity. MOCI factor 3 (concern about appearance and cleanliness) did not show any significant correlation with any of the BIS-11 sub-scores, suggesting that this personality trait most likely represents an obsessive-compulsive dimension orthogonal to impulsivity.

In an earlier report Stein et al. (1995) examined impulsivity in 431 patients with OCD using the Barratt Impulsivity Scale version 10-R (BIS-10R; Barratt and Patton, 1983) and the Yale-Brown Obsessive-Compulsive Scale (Y-BOCS). Without correcting for multiple comparisons, they found that there were small but 
significant positive correlations between the BIS total score and the Y-BOCS total score and the compulsion sub-score, but not between the BIS total score and the Y-BOCS obsession sub-score. The authors suggested that perhaps the underlying impulsivity in patients with OCD leads to increased OC symptoms or perhaps that both impulsivity and $\mathrm{OC}$ symptoms reflect common pathogenic mechanisms. These correlations in OCD patients thus stand in contrast to our current findings, where the only positive correlation was observed between doubting and intrusive thoughts (an obsession) and lack of perseveration and self-control in male participants. This discrepancy may suggest important differences between clinical and community samples.

Our current results also suggested potential gender differences in the association between obsessivecompulsiveness and impulsivity: A negative correlation between repetitive checking (MOCI factor 1) and lack of perseverance and self-control (BIS-11 factor 2) and between repetitive checking (MOCI factor 1) and novelty-seeking and acting without thinking (BIS-11 factor 3) was found for female but not male participants. Conversely, a positive correlation between doubting and intrusive thoughts (MOCI factor 2) and lack of perseverance and self-control (BIS-11 factor 2) was found only for male participants. These findings are interesting, considering that gender differences have been observed for clinical and genetic characteristics in OC spectrum and related disorders (Lochner and Stein, 2001; Ladd and Petry, 2002; Petry et al., 2002; Lochner et al., 2004). In particular, these findings indicate the need to examine gender differences in the symptomatic manifestations of OCSD.

Taken together, the current results suggest that obsessive-compulsiveness and impulsivity as assessed by the MOCI and the BIS-11 comprise multiple psychological constructs. The MOCI measures repetitive checking, doubting and intrusive thoughts, and concern over cleanliness while the BIS-11 describes inability to plan ahead, lack of perseverance and acting without thinking, although these behavioral dimensions remain to be confirmed and expanded. The current findings also suggest the utility of describing specific aspects of obsessive-compulsiveness and impulsivity in behavioral and clinical studies. For instance, Simeon et al. (1995) categorized self-injurious behaviors (SIB) as compulsive or impulsive SIB. Compulsive SIB such as hair-pulling and skin-picking, is habitual and repetitive, with individuals showing resistance to these ego-dystonic urges. Impulsive SIB such as skin cutting and burning, on the other hand, is episodic and often triggered by external events, with individuals showing little resis- tance to the ego-syntonic urges. What distinguish compulsive and impulsive SIB appear to be the temporal pattern (repetitive versus episodic) and associated affect (dystonic versus syntonic) of such behaviors. Other aspects of compulsion (as such intrusive thoughts) and impulsivity (such as failure to plan ahead) should not be automatically subsumed under such distinctions. Thus, neurobiological studies seeking to identify genetic and neuronal markers of obsessive-compulsiveness and impulsivity, as well as behavioral studies to dissect OCSD symptoms, would find it useful to distinguish among the sub-components of these behavioral traits (Stein et al., 1996; Steiger et al., 2003; Moritz et al., 2004).

\subsection{Conclusion and limitations of the study}

In summary, earlier studies have shown that patients with OCD-like OCSD and ICD show an increase in MOCI and BIS scorings, respectively (Muller et al., 1997; Krochmalik et al., 2001; Lejoyeux et al., 2002; Goveas et al., 2004; Martins et al., 2004). These two questionnaires have also been associated in these patients with altered serotoninergic function (Bastani et al., 1991; Goveas et al., 2004; Cools et al., 2005), which is widely believed to be implicated in the etiology of OCSD. Therefore, to the extent that the two questionnaires can capture the psychology and perhaps even the neurobiology in patients with OCD and ICD, the current results suggest associations between obsessive-compulsiveness and impulsivity that warrant further studies in patients with OCSD. These results may also be of importance in subtyping OCD (McKay et al., 2004; Morer et al., 2006).

A few important limitations of the study should be considered. First, we did not translate the Chinese version of the questionnaires back to English to examine the validity of the translation. Second, although the internal consistency of both the MOCI and the BIS-11 as applied to the current adolescent population appears to be satisfactory, the total amount of variance explained by the identified factors remains low. In particular, the corrected item-total correlation of the MOCI is only 0.265 , suggesting that our version may not be unidimensional. Therefore, the validity of using these two questionnaires in young Chinese subjects remains to be established. Third, although the current results largely replicated earlier findings, the number of factors identified based on PCA and factor rotation should be considered as specific to the current work. An item-byitem comparison would be required to identify those components that may be common to different languages and cultures. Lastly, it remains to be seen whether the 
association between the MOCI and BIS-11 component scores identified in the current study can be extended to patient populations, in particular, patients with OCSD.

\section{Acknowledgments}

We thank all of the students who participated in our study and the school authority for its facility. We also thank Ya-Ping Lee for carrying out the questionnaire interviews and the late Dr. Ernest Barratt (BIS-11) and Dr. Raymond Hodgson (MOCI) for allowing us to translate the questionnaires into Chinese for this work. This study is supported by a grant (CMRP792) from the Chang Gung Memorial Hospital.

\section{References}

Anholt, G.E., Emmelkamp, P.M., Cath, D.C., van Oppen, P., Nelissen, H., Smit, J.H., 2004. Do patients with OCD and pathological gambling have similar dysfunctional cognitions? Behavioral Research and Therapy 42, 529-537.

Apter, A., Horesh, N., Gothelf, D., Zalsman, G., Erlich, Z., Soreni, N., Weizman, A., 2003. Depression and suicidal behavior in adolescent inpatients with obsessive compulsive disorder. Journal of Affective Disorder 75, 181-189.

Barratt, E., Patton, J., 1983. Impulsivity: cognitive, behavioral, and psychophysiological correlates. In: Zuckerman, M. (Ed.), Biological Bases of Impulsiveness and Sensation Seeking. Laurence Erlbaum, Hillsdale, NJ.

Bastani, B., Arora, R.C., Meltzer, H.Y., 1991. Serotonin uptake and imipramine binding in the blood platelets of obsessive-compulsive disorder patients. Biological Psychiatry 30, 131-139.

Bienvenu, O.J., Sameuls, J.F., Riddle, M.A., Hoehn-Saric, R., Liang, K.Y., Cullen, B.A.M., Grados, M.A., Nestadt, G., 2000. The relationship of obsessive-compulsive disorder to possible spectrum disorders: results from a family study. Biological Psychiatry 48, 287-293.

Cath, D.C., Spinhoven, P., Hoogduin, C.A., Landman, A.D., van Woerkom, T.C., van de Wetering, B.J., Roos, R.A., Rooijmans, H.G., 2001. Repetitive behaviors in Tourette's syndrome and OCD with and without tics: what are the differences? Psychiatry Research 101, 171-185.

Chan, D.W., 1990. The Maudsley Obsessive-Compulsive Inventory: a psychometric investigation of Chinese normal subjects. Behaviour Research and Therapy 28, 413-420.

Christenson, G.A., Mackenzie, T.B., Mitchell, J.E., 1991. Characteristics of 60 adult chronic hair pullers. American Journal of Psychiatry 148, 365-370.

Cools, R., Blackwell, A., Clark, L., Menzies, L., Cox, S., Robbins, T.W., 2005. Tryptophan depletion disrupts the motivational guidance of goal-directed behavior as a function of trait impulsivity. Neuropsychopharmacology 30, 1362-1373.

Dent, H.R., Salkovskis, P.M., 1986. Clinical measures of depression, anxiety and obsessionality in non-clinical sample. Behaviour Research and Therapy 24, 689-691.

Emmelkamp, P.M., Kraaijkamp, H.J., van den Hout, M.A., 1999. Assessment of obsessive-compulsive disorder. Behavioral Modification 23, 269-279.
Fossati, A., Di Ceglie, A., Acquarini, E., Barratt, E.S., 2001. Psychometric properties of an Italian version of the Barratt Impulsiveness Scale-11 (BIS-11) in nonclinical subjects. Journal of Clinical Psychology 57, 815-828.

Frost, R.O., Meagher, B.M., Riskind, J.H., 2001. Obsessivecompulsive features in pathological lottery and scratch-ticket gamblers. Journal of Gambling Studies 17, 5-19.

Goveas, J.S., Csernansky, J.G., Coccaro, E.F., 2004. Platelet serotonin content correlates inversely with life history of aggression in personality-disordered subjects. Psychiatry Research 126, 23-32.

Guerrero, A.P., Hishinuma, E.S., Andrade, N.N., Bell, C.K., Kurahara, D.K., Lee, T.G., Turner, H., Andrus, J., Yuen, N.Y., Stokes, A.J., 2003. Demographic and clinical characteristics of adolescents in Hawaii with obsessive-compulsive disorder. Archives of Pediatrics and Adolescent Medicine 157, 665-670.

Hodgson, R.J., Rachman, S., 1977. Obsessional-compulsive complaints. Behaviour Research and Therapy 15, 389-395.

Hoehn-Saric, R., Barksdale, V.C., 1983. Impulsiveness in obsessivecompulsive patients. British Journal of Psychiatry 143, 177-182.

Hollander, E., Wong, C.M., 1995. Obsessive-compulsive spectrum disorders. Journal of Clinical Psychiatry 56 (Suppl. 4), 3-6.

Hollander, E., Kwon, J.H., Stein, D.J., Broatch, J., Rowland, C.T., Himelein, C.A., 1996. Obsessive compulsive spectrum disorders: overview and quality of life issues. Journal of Clinical Psychiatry 57 (Suppl. 8), 3-6.

Ketzenberger, K.E., Forrest, L., 2000. Impulsiveness and compulsiveness in alcoholics and nonalcoholics. Addictive Behaviors 25, 791-795.

Kim, S.W., Grant, J.E., 2001. Personality dimensions in pathological gambling disorder and obsessive-compulsive disorder. Psychiatry Research 104, 205-212.

Krochmalik, A., Jones, M.K., Menzies, R.G., 2001. Danger Ideation Reduction Therapy (DIRT) for treatment-resistant compulsive washing. Behaviour Research and Therapy 39, 897-912.

Lacey, J.H., Evans, C.D.H., 1986. The impulsivist: a multi-impulsive personality disorder. British Journal of Addiction 81, 641-649.

Ladd, G.T., Petry, N.M., 2002. Gender differences among pathological gamblers seeking treatment. Experimental and Clinical Psychopharmacology 10, 302-309.

Lejoyeux, M., Arbaretaz, M., McLoughlin, M., Ades, J., 2002. Impulse control disorders and depression. Journal of Nervous and Mental Disease 190, 310-314.

Lochner, C., Stein, D.J., 2001. Gender in obsessive-compulsive disorder and obsessive-compulsive spectrum disorders - a literature review. Archives of Women's Mental Health 4, 19-26.

Lochner, C., Hemmings, S.M., Kinnear, C.J., Moolman-Smook, J.C., Corfield, V.A., Knowles, J.A., Niehaus, D.J., Stein, D.J., 2004. Gender in obsessive-compulsive disorder: clinical and genetic findings. European Neuropsychopharmacology 14, 105-113.

Lochner, C., Seedat, S., du Toit, P.L., Nel, D.G., Niehaus, D.J., Sandler, R., Stein, D.J., 2005. Obsessive-compulsive disorder and trichotillomania: a phenomenological comparison. BMC Psychiatry 5, 2.

Martins, S.S., Tavares, H., da Silva Lobo, D.S., Galetti, A.M., Gentil, V., 2004. Pathological gambling, gender, and risk-taking behaviors. Addictive Behaviors 29, 1231-1235.

Mathews, C.A., Waller, J., Glidden, D., Lowe, T.L., Herrera, L.D., Budman, C.L., Erenberg, G., Naarden, A., Bruun, R.D., Freimer, N.B., Reus, V.I., 2004. Self injurious behaviour in Tourette syndrome: correlates with impulsivity and impulse control. Journal of Neurology, Neurosurgery and Psychiatry 75, 1149-1155.

Matsunaga, H., Kiriike, N., Matsui, T., Oya, K., Okino, K., Stein, D.J., 2005. Impulsive disorders in Japanese adult patients with obsessivecompulsive disorder. Comprehensive Psychiatry 46, 43-49. 
McElroy, S.L., Phillips, K.A., Keck, P.E., 1994. Obsessive compulsive spectrum disorder. Journal of Clinical Psychiatry 55 (Suppl. 10), 33-51.

McElroy, S.L., Pope, H.G., Keck, P.E., Hudson, J.I., 1995. Disorders of impulse control. In: Hollander, E., Stein, D. (Eds.), Impulsivity and Aggression. John Wiley and Sons, Sussex, England, pp. 109-136.

McKay, D., Abramowitz, J.S., Calamari, J.E., Kyrios, M., Radomsky, A., Sookman, D., Taylor, S., Wilhelm, S., 2004. A critical evaluation of obsessive-compulsive disorder subtypes: symptoms versus mechanisms. Clinical Psychology Review 24, 283-313.

Morer, A., Vinas, O., Lazaro, L., Calvo, R., Andres, S., Bosch, J., Gasto, C., Massana, J., Castro, J., 2006. Subtyping obsessivecompulsive disorder: clinical and immunological findings in child and adult onset. Journal of Psychiatric Research 40, 207-213.

Moritz, S., Meier, B., Hand, I., Schick, M., Jahn, H., 2004. Dimensional structure of the Hamilton Depression Rating Scale in patients with obsessive-compulsive disorder. Psychiatry Research 125, 171-180.

Müller, N., Putz, A., Kathmann, N., Lehle, R., Günther, W., Straube, A., 1997. Characteristics of obsessive-compulsive symptoms in Tourette's syndrome, obsessive-compulsive disorder, and Parkinson's disease. Psychiatry Research 70, 105-114.

Niehaus, D.J., Emsley, R.A., Brink, P., Stein, D.J., 2000. Stereotypies: prevalence and association with compulsive and impulsive symptoms in college students. Psychopathology 33, 31-35.

Patton, J.H., Stanford, M.S., Barratt, E.S., 1995. Factor structure of the Barratt Impulsiveness Scale. Journal of Clinical Psychology 51, 768-774

Petry, N.M., Kirby, K.N., Kranzler, H.R., 2002. Effects of gender and family history of alcohol dependence on a behavioral task of impulsivity in healthy subjects. Journal of Studies on Alcohol 63, 83-90.

Phillips, K.A., McElroy, S.L., Keck, P.E., Hudson, J.I., Pope, H.G., 1994. A comparison of delusional and non-delusional body dysmorphic disorder in 100 cases. Psychopharmacology Bulletin 30, 179-186.

Rasmussen, S.A., Eisen, J.L., 1994. The epidemiology and differential diagnosis of obsessive compulsive disorder. Journal of Clinical Psychiatry 55, 5-10.

Sanavio, E., Vidotto, G., 1985. The components of the Maudsley Obsessive-Compulsive Questionnaire. Behaviour Research and Therapy 23, 659-662.

Sherman, E.M., Shepard, L., Joschko, M., Freeman, R.D., 1998. Sustained attention and impulsivity in children with Tourette syndrome: comorbidity and confounds. Journal of Clinical and Experimental Neuropsychology 20, 644-657.

Shoval, G., Zalsman, G., Sher, L., Apter, A., Weizman, A., 2006. Clinical characteristics of inpatient adolescents with severe obsessivecompulsive disorder. Depression and Anxiety 23, 62-70.
Simeon, D., Hollander, E., Stein, D.J., Cohen, L., Aronowitz, B., 1995 Body dysmorphic disorder in the DSM-IV field trial for obsessivecompulsive disorder. American Journal of Psychiatry 152, 1207-1209.

Skodol, A.E., Oldham, J.M., 1995. Phenomenology, differential diagnosis and comorbidity of the impulsive-compulsive spectrum disorders. In: Hollander, E., Stein, D.J. (Eds.), Impulsivity and Aggression. Wiley, Sussex, UK, pp. 1-36.

Someya, T., Sakado, K., Seki, T., Kojima, M., Reist, C., Tang, S.W., Takahashi, S., 2001. The Japanese version of the Barratt Impulsiveness Scale, 11th version (BIS-11): its reliability and validity. Psychiatry and Clinical Neuroscience 55, 111-114.

Steiger, H., Israel, M., Gauvin, L., Ng Ying Kin, N.M., Young, S.N., 2003. Implications of compulsive and impulsive traits for serotonin status in women with bulimia nervosa. Psychiatry Research 120, 219-229.

Stein, D.J., Mullen, L., Islam, M.N., Cohen, L., Decaria, C.M., Hollander, E., 1995. Compulsive and impulsive symptomatology in trichotillomania. Psychopathology 28, 208-213.

Stein, D.J., Trestman, R.L., Mitropoulou, V., Coccaro, E.F., Hollander, E., Siever, L.J., 1996. Impulsivity and serotonergic function in compulsive personality disorder. Journal of Neuropsychiatry and Clinical Neuroscience 8, 393-398.

Stephens, R.J., Sandor, P., 1999. Aggressive behaviour in children with Tourette syndrome and comorbid attention-deficit hyperactivity disorder and obsessive-compulsive disorder. Canadian Journal of Psychiatry 44, 1036-1042.

Sternberger, L.G., Burns, G.L., 1990. Maudsley ObsessionalCompulsive Inventory: obsessions and compulsions in a nonclinical sample. Behaviour Research and Therapy 28, 337-340.

Støylen, I.J., Larsen, S., Kvale, G., 2000. The Maudsley ObsessionalCompulsive Inventory and OCD in a Norwegian nonclinical sample. Scandinavian Journal of Psychology 41, 283-286.

Swedo, S.E., Leonard, H.L., 1992. Trichotillomania: an obsessive compulsive spectrum disorder? Psychiatric Clinics of North America 15, 777-790.

Tadai, T., Nakamura, M., Okazaki, S., Nakajima, T., 1995. The prevalence of obsessive-compulsive disorder in Japan: a study of students using the Maudsley Obsessional-Compuslive Inventory and DSM-III-R. Psychiatry and Clinical Neuroscience 49, 39-41.

Thomas, J., Turkheimer, E., Oltmanns, T.F., 2000. Psychometric analysis of racial differences on the Maudsley Obsessional Compulsive Inventory. Assessment 7, 247-258.

Veale, D., Boocock, A., Gournay, K., Dryden, W., Shah, F., Willson, R., Walburn, J., 1996. Body dysmorphic disorder: a survey of 50 cases. British Journal of Psychiatry 169, 196-201.

Zohar, A.H., Bruno, R., 1997. Normative and pathological obsessivecompulsive behavior and ideation in childhood: a question of timing. Journal of Child Psychology and Psychiatry 38, 993-999. 